\title{
Angiotensin-converting enzyme inhibitor for post-transcatheter aortic valve implantation patients: study protocol for a multicenter randomized, open-label blinded endpoint control trial
}

Yan Biao Liao ${ }^{\dagger}$, Congying Xia ${ }^{\dagger}$ (1), Yiheng Cheng, Qiao Li, Xin Wei, Yuanweixiang Ou, Fei Chen, Yijian Li, Qi Liu, Tianyuan Xiong, Zhengang Zhao, Yong Peng, Jiafu Wei, Yuan Feng ${ }^{*}$ and Mao Chen ${ }^{*}$

\begin{abstract}
Background: With the expanded utilization of transcatheter aortic valve implantation (TAVI) to younger and lower surgical risk patients with severe aortic stenosis (AS), optimal medical therapy after TAVI procedure has become the main concern. Renin-angiotensin system inhibitors (RASi) are widely utilized in the area of cardiovascular disease including heart failure and myocardial infarction and revealed the ability to reverse left ventricular (LV) remodeling. Interests have, thus, been drawn in investigating whether the prescription of RASi after the TAVI procedure can prevent or reverse cardiac remodeling and improve long-term clinical outcomes. No recommendation regarding the prescription of RASi after TAVI is proposed yet due to the lack of evidence from randomized controlled trials, especially in the Chinese population. We, therefore, designed this randomized controlled trial to explore the effect of adding fosinopril to standard care in patients who underwent a successful TAVI procedure on the LV remodeling.

Methods: A total of 200 post-TAVI patients from seven academic hospitals across China will be recruited and randomized with a ratio of 1:1 to receive standard care or standard care plus fosinopril. Follow-up visits will take place at 30 days, 3 months, 6 months, 12 months, and 24 months from randomization to assess the clinical symptoms, any adverse events, cardiac function, and quality of life. Cardiac magnetic resonance will be performed at baseline and repeated at the 24-month follow-up visit to assess LV remodeling.
\end{abstract}

Discussion: This study will provide evidence regarding medical therapy for AS patients who underwent TAVI and filling the gap in the Chinese population.

Trial registration: Chinese Clinical Trial Registry ChiCTR2100042266. Registered on 17 January 2021

Keywords: Aortic stenosis, Fosinopril, Left ventricle mass, Renin-angiotensin system inhibitor, Prognosis

\footnotetext{
*Correspondence: fynotebook@hotmail.com; hmaochen@vip.sina.com

${ }^{\dagger}$ YanBiao Liao and Congying Xia are co-first authors.

Department of Cardiology, West China Hospital, Sichuan University,

Chengdu, China
}

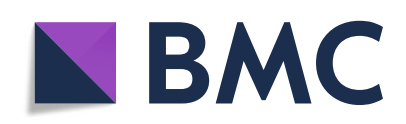

( ) The Author(s). 2021 Open Access This article is licensed under a Creative Commons Attribution 4.0 International License, which permits use, sharing, adaptation, distribution and reproduction in any medium or format, as long as you give appropriate credit to the original author(s) and the source, provide a link to the Creative Commons licence, and indicate if changes were made. The images or other third party material in this article are included in the article's Creative Commons licence, unless indicated otherwise in a credit line to the material. If material is not included in the article's Creative Commons licence and your intended use is not permitted by statutory regulation or exceeds the permitted use, you will need to obtain permission directly from the copyright holder. To view a copy of this licence, visit http://creativecommons.org/licenses/by/4.0/ The Creative Commons Public Domain Dedication waiver (http://creativecommons.org/publicdomain/zero/1.0/) applies to the data made available in this article, unless otherwise stated in a credit line to the data. 


\section{Administrative information}

Note: the numbers in curly brackets in this protocol refer to SPIRIT checklist item numbers. The order of the items has been modified to group similar items (see http://www.equator-network.org/reporting-guidelines/ spirit-2013-statement-defining-standard-protocol-itemsfor-clinical-trials/).

\begin{tabular}{|c|c|}
\hline Title $\{1\}$ & $\begin{array}{l}\text { Angiotensin-converting enzyme } \\
\text { inhibitor for post transcatheter aortic } \\
\text { valve implantation patients: study } \\
\text { protocol for a multicenter randomized, } \\
\text { open-label blinded endpoint control } \\
\text { trial }\end{array}$ \\
\hline Trial registration $\{2 \mathrm{a}$ and $2 \mathrm{~b}\}$. & $\begin{array}{l}\text { This study was registered at the } \\
\text { Chinese Clinical Trial Registry (http:// } \\
\text { www.chictr.org.cn), } 17 \text { January 2021. } \\
\text { The registration number is } \\
\text { ChiCTR2100042266. }\end{array}$ \\
\hline Protocol version $\{3\}$ & Version 1.1 \\
\hline Funding $\{4\}$ & $\begin{array}{l}\text { This randomized trial is funded by a } \\
\text { grant from the Chinese Association of } \\
\text { Cardiology (CSCF2020B04). }\end{array}$ \\
\hline Author details $\{5 a\}$ & $\begin{array}{l}\text { YanBiao Liao, Congying Xia, Yiheng } \\
\text { Cheng, Qiao Li, Xin Wei, Yuanweixiang } \\
\text { Ou, Fei Chen, Yijian Li, Qi Liu, Tianyuan } \\
\text { Xiong, Zhengang Zhao, Yong Peng, } \\
\text { Jiafu Wei, Yuan Feng, Mao Chen } \\
\text { Authors are all from Department of } \\
\text { Cardiology, West China Hospital, } \\
\text { Sichuan University, Chengdu, China }\end{array}$ \\
\hline $\begin{array}{l}\text { Name and contact information } \\
\text { for the trial sponsor }\{5 b\}\end{array}$ & $\begin{array}{l}\text { Chinese Medical Association } \\
\text { Cardiovascular Branch (CSC) Clinical } \\
\text { Research Special Fund Project. } \\
\text { Yinghong Ai, +8613940094018, } \\
\text { xlzc@cardiounion.cn }\end{array}$ \\
\hline Role of sponsor $\{5 c\}$ & $\begin{array}{l}\text { This funding source had no role in the } \\
\text { design of this study and will not have } \\
\text { any role during its execution, analyses, } \\
\text { interpretation of the data, or decision } \\
\text { to submit results. }\end{array}$ \\
\hline
\end{tabular}

\section{Introduction}

\section{Background and rationale $\{6 a\}$}

Aortic stenosis (AS) is the most common valvular heart disease in the elderly population [1]. With the acceleration of the Chinese population aging, the prevalence of aortic stenosis is thought to increase markedly. Surgical aortic valve replacement (SAVR) is regarded as the only effective method for patients with aortic stenosis in the past decades. However, numerous evidence have demonstrated transcatheter aortic valve implantation (TAVI) to be comparable and sometimes superior in treating patients with aortic stenosis regardless of risk stratification, in comparison with SAVR [2].

Patients with aortic stenosis typically accompany with left ventricular (LV) hypertrophy or fibrosis indicating a worse long-term clinical outcome [3]. A majority of patients continue to present left ventricular hypertrophy even after SAVR or TAVI, who had a high risk for mortality and heart failure re-admission [4]. A previous meta-analysis found that the 30-day and 1-year incidence of re-admission following TAVI was $15 \%$ and $31 \%$, respectively, of which nearly half resulted from the cardiac cause [5]. Compared with that of SAVR, TAVI is associated with a high risk for paravalvular leakage, even in patients with a new-generation transcatheter heart valve. The persistent left ventricular hypertrophy and new-onset paravalvular leakage after TAVI will negatively affect the prognosis especially when TAVI moves toward to treating patients at a young age.

Renin-angiotensin system inhibitors (RASi) are widely utilized in the area of cardiovascular disease including heart failure, myocardial infarction, and so on due to the ability to reversing the left ventricular remodeling $[6,7]$. Candesartan was documented to be associated with positive improvement in left ventricular remodeling in patients with preserved left ventricular ejection fraction (LVEF) after SAVR in a randomized controlled trial [8]. Similarly, several retrospective studies also demonstrated RASi could reduce the occurrence rate of heart failure re-admission and mortality in patients with aortic stenosis after SAVR and TAVI [9-11]. However, no recommendation regarding the prescription of RASi after TAVI was proposed yet due to lacking randomized controlled trials.

Therefore, we designed this randomized controlled trial (http://www.chictr.org.cn ChiCTR2100042266) to explore the effect of adding fosinopril to standard care in patients with preserved LVEF following successful TAVI procedure on the left ventricular remodeling and fibrosis as evaluated by cardiac magnetic resonance (CMR) and echocardiography.

\section{Objectives $\{7\}$}

The primary objective of this trial is to investigate the efficacy of RASi in the improvement of left ventricular remodeling quantified by CMR in patients after TAVI. The secondary objective is to assess potential improvements in clinical outcomes including all-cause mortality, cardiac-cause mortality, heart failure status assessed by the New York Heart Association (NYHA) class, and 6-min walk test (6MWT), and quality of life as assessed by the Kansas City Cardiomyopathy Questionnaire (KCCQ) score.

\section{Trial design $\{8\}$}

This study will be a prospective, randomized, open-label blinded endpoint control trial in symptomatic patients with severe AS. This study protocol was approved by the institutional ethics committee of West China Hospital of Sichuan University and the local medical ethics committee of each participating center. 


\section{Methods: participants, interventions, and outcomes}

\section{Study setting $\{9\}$}

This trial will take place at seven academic medical centers across China. The list of the involved hospitals is presented in supplemental table 1.

\section{Eligibility criteria $\{10\}$}

Symptomatic patients with severe AS after the TAVI procedure will be randomized to receive either conventional treatment or conventional treatment plus fosinopril. Severe AS is determined according to echocardiography measures: (1) aortic valve area $\leq 1.0$ $\mathrm{cm}^{2}$ or aortic valvular area index $\leq 0.6 \mathrm{~cm}^{2} / \mathrm{m}^{2}$ and (2) peak aortic jet velocity $\geq 4 \mathrm{~m} / \mathrm{s}$ or mean transaortic valvular pressure gradient $\geq 40 \mathrm{mmHg}$.

\section{Inclusion criteria}

Subjects need to meet all the following inclusion criteria to participate in the study: (1) men or women aged $\geq 60$ years, (2) presenting with symptomatic severe AS, (3) have undergone TAVI successfully which have to be approved by the local heart team according to the Valve Academic Research Consortium-2 consensus document [12], (4) heart failure is classified as function capacity level I according to the NYHA, (5) LVEF $\geq 40 \%$ assessed by echocardiography, and (6) being able to understand and provide written informed consent.

\section{Exclusion criteria}

Subjects presenting any of the following exclusion criteria will be excluded from the study: (1) concomitant with other significant valvular heart disease needs intervention; (2) contraindication or intolerance for the use of fosinopril including a history of angioneurotic edema, hypotension (defined as systolic blood pressure $<100 \mathrm{mmHg}$ or diastolic blood pressure $<60 \mathrm{mmHg}$ ), estimated glomerular filtration rate $<30 \mathrm{~mL} / \mathrm{min} / 1.73 \mathrm{~m}^{2}$, and random serum potassium $>$ $5.4 \mathrm{mmol} / \mathrm{L}$; (3) life expectancy < 1 year; (4) contraindication to CMR, f.e., implantation of cardiac resynchronization therapy devices that are non-magnetic resonance conditional; and (5) prior history of myocardial infarction or dilated cardiomyopathy.

\section{Who will take informed consent? $\{26 \mathrm{a}\}$}

Written informed consent will be collected from all participants. A researcher from the local heart team, who is trained with the study protocol will confirm the patient's willingness to participate and eligibility criteria and obtain an informed consent.

Additional consent provisions for collection and use of participant data and biological specimens $\{26 \mathrm{~b}\}$

Not applicable

\section{Interventions}

Explanation for the choice of comparators $\{6 b\}$

Patients allocated in the control group will receive standard care according to the current practice.

\section{Intervention description \{11a\}}

Patients allocated in the intervention group will receive an additional use of fosinopril with an initial dose of 10 mg once daily. If the patient is well-tolerated, they will be titrated to a maximum dose of $40 \mathrm{mg}$ once daily. Titration of fosinopril will be performed at the 1-month follow-up visit and afterward.

\section{Criteria for discontinuing or modifying allocated interventions $\{11 b\}$}

Participants are allowed to discontinue and end their participation in the trial at any time for any reason. Researchers can decide to withdraw a participant from the trial at any time when encountering emergency circumstances and/or for any urgent medical reasons.

\section{Strategies to improve adherence to interventions $\{11 \mathrm{c}\}$}

A standard operating procedure was created for the administration of treatment of intervention and control group. Research assistants will help educate the patients. Adherence to the use of fosinopril will be assessed during follow-up visits.

\section{Relevant concomitant care permitted or prohibited during the trial $\{11 d\}$}

In the case of patients allocated in the control group and who need to be treated for hypertension, the local Heart Team will make the decision without prescribing any RASi.

\section{Provisions for post-trial care \{30\}}

We expect that intervention-related severe adverse events in this trial will be unlikely because the use of RASi in patients with heart failure is a routine regimen in current practice. Nevertheless, we plan to provide health care at each study site for participants who may encounter trial procedure-related medical situations that need ancillary care. Post-trial care will not be provided.

\section{Outcomes $\{12\}$}

The primary outcome of this trial is the changes in LV mass index. The secondary outcomes include the following: (1) changes in LVEF; (2) all-cause mortality; (3) cardiac death; (4) re-admission rate due to heart failure; (5) changes in serum $\mathrm{N}$ terminal pro B type natriuretic peptide (NT-ProBNP), a diagnostic biomarker for heart failure; (6) NYHA class, KCCQ scores, and results of 6MWT at 24 months follow-up; and (7) changes in NYHA class, KCCQ scores, and results of 6MWT. 


\section{Participant timeline $\{13\}$}

The workflow is depicted in the flowchart (Fig. 1); schedule of enrollment, intervention, and examinations are presented in Table 1.

\section{Sample size $\{14\}$}

The sample size is calculated based on the primary endpoint, namely the difference in changes of LV mass index at 24 months between the intervention group and the control group. Prior prospective studies reported a difference of 10 $\mathrm{g} / \mathrm{m}^{2}$ and $18 \mathrm{~g} / \mathrm{m}^{2}$ in absolute changes in LV mass index at 6 months and at 12 months, respectively, comparing with and without RASi treatment $[8,13]$. A sample size of 100 per group will have more than $90 \%$ power to detect an expected difference of $20 \mathrm{~g} / \mathrm{m}^{2}$ at an alpha level of 0.05 , given a standard deviation of $35 \mathrm{~g} / \mathrm{m}^{2}$ and a dropout rate of $10 \%$.

\section{Recruitment \{15\}}

Patients undergoing TAVI from seven academic medical centers across China will be screened for eligibility and recruited about 1 week after the TAVI procedure.

\section{Assignment of interventions: allocation Sequence generation \{16a\}}

Eligible patients will be randomized in a 1:1 ratio to receive standard care or standard care plus fosinopril.
Centralized random allocation will be performed after receipt of informed consent using a block size of 4 without stratification. Allocation sequence was generated using $\mathrm{R}$ with the package randomizeR prior to study initiation.

\section{Concealment mechanism \{16b\}}

Generated allocation sequence is to be concealed in opaque, sealed envelopes that are consecutively numbered. An independent research assistant is responsible for keeping these envelopes unopened and allocated.

\section{Implementation $\{16 c\}$}

The allocation sequence will be generated by a statistician. Participants who are eligible for this trial and willing to give written consent will be enrolled by a trial researcher. The research assistant will directly inform the clinician about the group allocation.

\section{Assignment of interventions: blinding \\ Who will be blinded $\{17 a\}$}

Due to logistic reasons, it will not be feasible to blind the natural course of this study to patients nor clinicians. However, all endpoints will be adjudicated by an independent imaging core lab or the clinical event committee, who are blinded to the group allocation.

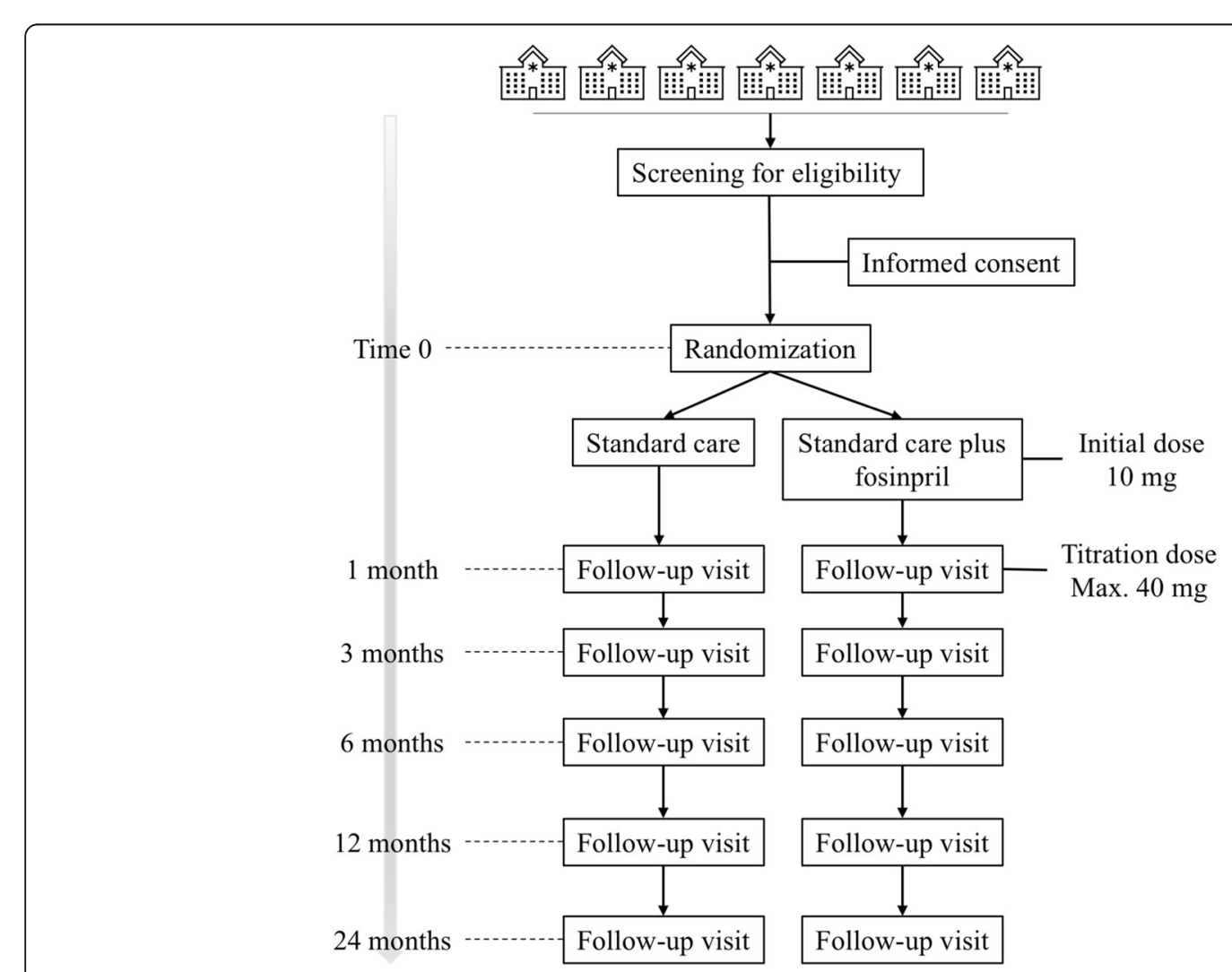

Fig. 1 Flowchart of the study design 
Table 1 Schedule of enrollment, interventions, and examinations

\begin{tabular}{|c|c|c|c|c|c|c|c|}
\hline \multirow[t]{3}{*}{ Time point } & \multicolumn{7}{|c|}{ Study period } \\
\hline & \multirow{2}{*}{$\begin{array}{l}\text { Enrolment } \\
1 \text { week pre }\end{array}$} & \multirow{2}{*}{$\begin{array}{l}\text { Allocation } \\
0\end{array}$} & \multicolumn{5}{|c|}{ Post-allocation } \\
\hline & & & 1 month & 3 months & 6 months & 12 months & 24 months \\
\hline \multicolumn{8}{|l|}{ Enrollment } \\
\hline Eligibility screen & $x$ & & & & & & \\
\hline Informed consent & $x$ & & & & & & \\
\hline Allocation & & $x$ & & & & & \\
\hline \multicolumn{8}{|l|}{ Interventions } \\
\hline Standard care & & & $x$ & $x$ & $x$ & $x$ & $x$ \\
\hline Standard care plus fosinopril & & & $x$ & $x$ & $x$ & $x$ & $x$ \\
\hline \multicolumn{8}{|l|}{ Assessments } \\
\hline Demographics & $x$ & & & & & & \\
\hline Physical examinations & $x$ & & $x$ & $x$ & $x$ & $x$ & $x$ \\
\hline Medical history & $x$ & & $x$ & $x$ & $x$ & $x$ & $x$ \\
\hline Laboratory tests & $x$ & & $x$ & $x$ & $x$ & $x$ & $x$ \\
\hline NYHA class & $x$ & & $x$ & $x$ & $x$ & $x$ & $x$ \\
\hline Transthoracic echocardiography & $x$ & & $x$ & $x$ & $x$ & $x$ & $x$ \\
\hline CMR & & $x$ & & & & & $x$ \\
\hline KCCQ & & $x$ & $x$ & $x$ & $x$ & $x$ & $x$ \\
\hline 6-min walk test & & $x$ & $x$ & $x$ & $x$ & $x$ & $x$ \\
\hline Adverse events & & & $x$ & $x$ & $x$ & $x$ & $x$ \\
\hline
\end{tabular}

NYHA New York Heart Association, CMR cardiac magnetic resonance, KCCQ Kansas City Cardiomyopathy Questionnaire

Procedure for unblinding if needed $\{17 b\}$

Not applicable, the trial is an open-label design.

\section{Data collection and management}

\section{Plans for assessment and collection of outcomes $\{18 a\}$}

Severe AS patients who underwent TAVI will be approached and consented for screening for eligibility. Screening evaluations include brief physical examinations, blood laboratory tests, and reviewing of medical history. Heart failure-related symptoms will be assessed for an NYHA functional classification. Transthoracic echocardiography will be conducted to assess cardiac function.

The following information will be collected during baseline evaluations: (1) demographics including date of birth, gender; (2) physical examinations including body weight, body height, resting pulse, and blood pressure; (3) any major previous health problems and use of medication by reviewing health records; (4) NYHA function capacity class by examining related symptoms; (5) results of laboratory tests including full blood count, blood lipids, glucose, liver function, renal function, and NT-ProBNP; (6) KCCQ score and results of 6MWT. Follow-up visits will take place 30 days, 3 months, 6 months, 12 months, and 24 months from randomization. At each follow-up visit, patients will be asked for any specific symptoms, any changes in the use of medication, and any adverse events. A brief physical examination will be performed to measure the resting pulse and blood pressure. Blood samples will be taken for the laboratory tests including NT-ProBNP. Transthoracic echocardiography will be performed to evaluate LV function. Moreover, NYHA function capacity class, KCCQ, and 6MWT will be evaluated. CMR scanning will be performed at baseline and be repeated at the 24-month follow-up visit to assess LV volume, mass, and function. CMR images will be analyzed independently by a central imaging core lab (West China Hospital Radiology Medicine lab). All endpoints will be adjudicated by an independent clinical events committee blinded for group allocation.

\section{Kansas City cardiomyopathy questionnaire}

KCCQ is used to assess patients' quality of life [14]. The KCCQ is self-administered, but patients can also complete the questionnaire by interview through a clinician. On average, it will take 4 to $6 \mathrm{~min}$ to complete the KCCQ.

\section{Six-minute walk test}

The 6MWT will be performed in an indoor hospital corridor at each participating site. The walking course is straight, flat, and at least $30 \mathrm{~m}$ in length. The starting line and every $3 \mathrm{~m}$ of the course are marked. Patients will be asked to walk along the corridor back and forth. Patients will be allowed to stop and rest or discontinue the test. 
The longest distance in $6 \mathrm{~min}$ will be measured to the nearest whole meter. In order to maintain consistency, all participating sites will use a standardized manual to guide operations, including standardized phrasing to give patients instructions and encouragement.

\section{Transthoracic echocardiography protocol}

Transthoracic echocardiography will be performed using commercially available ultrasound systems at each participating sites. In order to maintain consistency, all measurements will be performed according to the expert consensus on adult transthoracic echocardiography reporting [15].

\section{Cardiovascular magnetic resonance protocol}

CMR scanning will be performed using a 1.5-T scanner which is commercially available at local participating sites. An electrocardiography-triggering acquisition will be conducted for patients in supine position and breathhold at the end of expiration. Late gadolinium enhancement CMR was also conducted by the administration of $0.2 \mathrm{mmol} / \mathrm{kg}$ of gadolinium. After scout imaging, the long axis of the LV and four-chamber cine images will be acquainted using the balanced steady-state free precession (bSSFP) sequence with a slice thickness of $8 \mathrm{~mm}$ and interslice gap of $2 \mathrm{~mm}$. Imaging acquisition parameters are as follows: repetition time $34 \mathrm{~ms}$, echo time 1.3 $\mathrm{ms}$, flip angle $50^{\circ}$, average temporal resolution $35-45$ $\mathrm{ms}$, and field of view $280 \times 340 \mathrm{~mm}^{2}$.

Images will be evaluated using the Cvi42 version 5.12 software (Circle Cardiovascular Imaging Inc.) for LV mass, volumes, and function. LV mass is calculated by multiplying the difference between total epicardial volume and total endocardial volume with the density of myocardium $(1.05 \mathrm{~g} / \mathrm{mL})$. LV mass is then indexed to the surface area to achieve LV mass index [16].

\section{Plans to promote participant retention and complete follow-up $\{18 b\}$}

All reasonable efforts (such as by email and telephone call) will be made to complete the data collection including follow-up information for endpoints (if applicable) and the reason why participants want to quit the trial.

\section{Data management $\{19\}$}

A digital case reported form will be designed and used for data collection. All collected data will be stored and managed using a web-based data manage system. Researchers are responsible for the data collection, especially for checking that all data related to this trial are filled out in the data manage system correctly and completely. A data management plan will be created beforehand for data validation.

\section{Confidentiality $\{27\}$}

Personal data of the participants will be treated as confidential and stored securely during the whole course of this trial.

Plans for collection, laboratory evaluation, and storage of biological specimens for genetic or molecular analysis in this trial/future use $\{33\}$

Not applicable

\section{Statistical methods}

Statistical methods for primary and secondary outcomes $\{20$ a $\}$

The primary and secondary endpoints will be analyzed according to the intention-to-treat principle. To compare the primary endpoint, adjusted mean difference in changes in LV mass index at 24-month follow-up visit between the two groups will be tested using linear regression with adjustment for baseline values. Time-toevent comparison (f.e., secondary endpoints including all-cause mortality and cardiac death) between the groups will be conducted using log-rank test and proportional hazards regression. A two-sided p value of 0.05 will be considered statistically significant.

\section{Interim analyses $\{21 \mathrm{~b}\}$}

Not applicable, no interim analysis will be performed.

Methods for additional analyses (e.g., subgroup analyses) \{20b\}

For descriptive analyses of baseline characteristics, continuous variables will be presented as mean and standard deviation or median and interquartile range depends on the distribution. Categorical variables will be presented as frequencies and percentages. Differences between the groups will be tested using the independent t-test or Mann-Whitney $U$ test when appropriate for continuous variables and using the chi-square test or Fisher's exact test when appropriate for categorical variables.

\section{Methods in analysis to handle protocol non-adherence} and any statistical methods to handle missing data $\{20 \mathrm{c}\}$ All efforts will be made to complete the follow-up and data collection and avoid missing data. Analyses will be conducted in complete cases. We will also perform sensitivity analyses by imputing the missing data to worst cases.

Plans to give access to the full protocol, participant leveldata, and statistical code $\{31 \mathrm{c}\}$

Statistic plan and statistical code will be published together with the final reports after the whole trial is closed. There is no plan to release the participant-level 
dataset; however, access to the dataset will be possible upon reasonable requisition.

\section{Oversight and monitoring}

Composition of the coordinating center and trial steering committee $\{5 \mathrm{~d}\}$

The coordinating center is the West China Hospital. The trial steering committee consists of principal investigators at each study site responsible for interventions (standard care for the control group, standard care plus fosinopril for the intervention group). Other clinicians of the local Heart Team will be responsible for follow-up, data collection, and logistic support for the trial. The endpoint adjudication committee consists of an imaging core lab and two cardiologists.

\section{Composition of the data monitoring committee, its role,} and reporting structure $\{21 \mathrm{a}\}$

The data and safety monitoring committee (DSMC) will consist of four qualified members from the West China Hospital, including at least one statistician and cardiology expert independent from the site trial staff. The DSMC is independent from the trial researchers, blinded to the assignment, and will monitor the progress of the trial and safety issues and require data for analyses.

\section{Adverse event reporting and harms $\{22\}$}

Adverse events reported by the participant or noticed by the clinician will be reported directly (maximum within a week) to the DSMC and recorded in the digital case reported form and data manage system.
Frequency and plans for auditing trial conduct $\{23\}$

Audit reports will be given by the trained auditors at three different time points, namely after the first participant is enrolled, at 12 months after launching the trial, and before the trial is closed out. Eligibility of recruited participants, collection of consent, and data integrity will be checked at each study site.

\section{Plans for communicating important protocol} amendments to relevant parties (e.g., trial participants, ethical committees) $\{25\}$

A yearly update will be given to the ethics committee if any protocol amendment is supposed to be made in line with the updates for clinical practice. Amendments will be made only after a favorable opinion is given by the ethical committees. All site trial staff will be informed correspondently.

\section{Dissemination plans $\{31 \mathrm{a}\}$}

The trial results will be presented at international meetings and published in a peer-reviewed journal.

\section{Discussion}

With the expanded utilization of TAVI to a younger and lower surgical risk patient with severe AS, optimal medical therapy after TAVI procedure has become the main concern. Interests have been drawn in the investigation of medications that can improve cardiac remodeling and long-term clinical outcomes. Currently, a routine strategy of medical therapy after the TAVI procedure is not recommended due to insufficient evidence supporting the benefits. Previous studies found that the use of RASi may have the potential to prevent or reverse cardiac remodeling and improve prognosis with less inconsistent results $[8-10,13]$. Further

Table 2 Summary of randomized trials that investigated the effect of renin-angiotensin system blockade therapy after aortic valve replacement for severe aortic stenosis patients

\begin{tabular}{|c|c|c|c|c|c|c|c|c|c|}
\hline $\begin{array}{l}\text { Author, } \\
\text { year }\end{array}$ & Region & $\begin{array}{l}\text { Study } \\
\text { population }\end{array}$ & Study design & Registration & $\begin{array}{l}\text { Sample } \\
\text { size }^{\mathrm{a}}\end{array}$ & Interventions & Comparison & $\begin{array}{l}\text { Primary } \\
\text { outcomes }\end{array}$ & Status \\
\hline $\begin{array}{l}\text { Dahl } \\
\text { et al., } \\
2010 \text { [8] }\end{array}$ & $\begin{array}{l}\text { Denmark, } \\
\text { single } \\
\text { center }\end{array}$ & Post SAVR & $\begin{array}{l}\text { Randomized, } \\
\text { open-label, } \\
\text { blinded } \\
\text { endpoint }\end{array}$ & NCT00294775 & $61: 64$ & $\begin{array}{l}\text { Candesartan } \\
\text { treatment }\end{array}$ & $\begin{array}{l}\text { Conventional } \\
\text { treatment }\end{array}$ & $\begin{array}{l}\text { Change in LV } \\
\text { mass index }\end{array}$ & Completed \\
\hline $\begin{array}{l}\text { Amat- } \\
\text { Santos } \\
\text { et al., } \\
2018 \text { [17] }\end{array}$ & $\begin{array}{l}\text { Spain, } 8 \\
\text { centers }\end{array}$ & Post TAVI & $\begin{array}{l}\text { Randomized, } \\
\text { open-label, } \\
\text { blinded } \\
\text { endpoint }\end{array}$ & NCT03201185 & 168:168 & $\begin{array}{l}\text { Ramipril plus } \\
\text { standard care }\end{array}$ & Standard care & $\begin{array}{l}\text { Cardiac death or } \\
\text { heart failure } \\
\text { hospitalization or } \\
\text { stroke }\end{array}$ & Recruiting \\
\hline $\begin{array}{l}\text { Aboyans } \\
\text { et al. [18] }\end{array}$ & $\begin{array}{l}\text { France, } \\
\text { multicenter }\end{array}$ & $\begin{array}{l}\text { Post SAVR } \\
\text { or TAVI }\end{array}$ & $\begin{array}{l}\text { Randomized, } \\
\text { quadruple } \\
\text { blinded }\end{array}$ & NCT03315832 & 55:55 & Valsartan & Placebo & $\begin{array}{l}\text { Changes in LV } \\
\text { mass index }\end{array}$ & $\begin{array}{l}\text { Not yet } \\
\text { recruiting }\end{array}$ \\
\hline Liao et al. & $\begin{array}{l}\text { China, } 7 \\
\text { centers }\end{array}$ & Post TAVI & $\begin{array}{l}\text { Randomized, } \\
\text { open-label, } \\
\text { blinded } \\
\text { endpoint }\end{array}$ & ChiCTR2100042266 & 100:100 & $\begin{array}{l}\text { Fosinopril } \\
\text { plus standard } \\
\text { care }\end{array}$ & Standard care & $\begin{array}{l}\text { Change in LV } \\
\text { mass index }\end{array}$ & $\begin{array}{l}\text { Active, not } \\
\text { yet } \\
\text { recruiting }\end{array}$ \\
\hline
\end{tabular}

SAVR surgical aortic valve replacement, $L V$ left ventricle, TAVI transcatheter aortic valve intervention

${ }^{a}$ Number of patients in the intervention group versus the control group 
evidence from randomized control trials is warranted to clarify the effect of RASi in cardiac remodeling and long-term prognosis. Regarding this concern, we designed this randomized control trial to investigate the effect of the prescription of RASi, specifically fosinopril, after TAVI on cardiac remodeling, clinical outcomes, and quality of life. We also summarized other randomized trials regarding this topic (Table 2). Similarly, another study in Europe, the RAS blockade after TAVI (RASTAVI) study (http://www.ClinicalTrials.gov NCT03201185), which was designed to address whether the prescription of ramipril in postoperative AS patients can be beneficial is still ongoing [17]. Together, these studies will provide further evidence regarding medical therapy for AS patients who underwent TAVI, and our study will specifically fill the gap in the Chinese population.

\section{Trial status}

The recruitment of this study will be started in September 2021, and the last participant will be included in September 2023 anticipatedly.

\section{Abbreviations}

6MWT: Six-minute walk test; AS: Aortic stenosis; CMR: Cardiac magnetic resonance; DSMC: Data and safety monitoring committee; KCCQ: Kansas City Cardiomyopathy Questionnaire; LV: Left ventricular; LVEF: Left ventricular ejection fraction; NYHA: New York Heart Association; RASi: Renin-angiotensin system inhibitors; SAVR: Surgical aortic valve replacement; TAVI: Transcatheter aortic valve implantation

\section{Supplementary Information}

The online version contains supplementary material available at https://doi. org/10.1186/s13063-021-05411-5.

Additional file 1: Table 1. Study expected enrollment from seven medical centers in China.

\section{Acknowledgements}

We would like to thank all the participants and personnel pertaining to this trial. We also acknowledge Guanjian Liu and Fanfan Shi for their consultation on randomization strategies.

\section{Authors' contributions $\{31 \mathrm{~b}\}$}

YL and CX are co-first authors. YF and MC are corresponding authors. YF and $M C$ and the chief investigators led the study proposal and set up the study. $Y L$ and $C X$ contributed to the study design and drafted the manuscript. YC, $\mathrm{QL}, X W, Y O, F C, Y J L, Q L, T X, Z Z, Y P J W$, and YF are members of the steering committee, local researchers, and imaging labs of echocardiography and cardiac magnetic resonance, and they are responsible for data acquisition and analysis. All authors have read, reviewed, and approved the final manuscript.

\section{Funding $\{4\}$}

This randomized trial is funded by a grant from the Chinese Association of Cardiology (CSCF2020B04).

\section{Availability of data and materials $\{29\}$}

There is no plan for public access to the dataset of this trial at this moment. However, the dataset will be available from the corresponding authors upon reasonable request after the trial is completed.

\section{Authors' information}

None.

\section{Declarations}

\section{Ethics approval and consent to participate $\{24\}$}

This study protocol was approved by the institutional ethics committee of West China Hospital of Sichuan University and the local medical ethics committee of each participating center. Written informed consent will be collected from all participants.

Consent for publication $\{32\}$

Not applicable

\section{Competing interests $\{28\}$}

Dr. Chen and Feng are consultants and proctors for Venus MedTech, MicroPort, and TaurusOne. All other authors declare that they have no competing interests.

Received: 3 May 2021 Accepted: 30 June 2021

Published online: 18 July 2021

\section{References}

1. Carabello BA, Paulus WJ. Aortic stenosis. Lancet. 2009;373(9667):956-66.

2. Mack MJ, Leon MB, Thourani VH, Makkar R, Kodali SK, Russo M, et al. Transcatheter aortic-valve replacement with a balloon-expandable valve in low-risk patients. N Engl J Med. 2019;380(18):1695-705. https://doi.org/10.1 056/NEJMoa1814052.

3. Treibel TA, Badiani S, Lloyd G, Moon JC. Multimodality imaging markers of adverse myocardial remodeling in aortic stenosis. J Am Coll Cardiol Img. 2019;12(8 Pt 1):1532-48. https://doi.org/10.1016/j.jcmg.2019.02.034.

4. Lindman BR, Stewart WJ, Pibarot P, Hahn RT, Otto CM, Xu K, et al. Early regression of severe left ventricular hypertrophy after transcatheter aortic valve replacement is associated with decreased hospitalizations. JACC Cardiovasc Interv. 2014;7(6):662-73. https://doi.org/10.1016/j.jcin.2014.02.011.

5. Li YM, Mei FY, Yao YJ, Tsauo JY, Peng Y, Chen M. Causes and predictors of readmission after transcatheter aortic valve implantation : A meta-analysis and systematic review. Herz. 2021;46(Suppl 1):1-8. English. https://doi.org/1 0.1007/s00059-019-04870-6. Epub 2019 Dec 5.

6. Bangalore S, Fakheri R, Wandel S, Toklu B, Wandel J, Messerli FH. Renin angiotensin system inhibitors for patients with stable coronary artery disease without heart failure: systematic review and meta-analysis of randomized trials. BMJ. 2017;356:j4.

7. Yancy CW, Jessup M, Bozkurt B, Butler J, Casey DE Jr, Drazner MH, et al. 2013 ACCF/AHA guideline for the management of heart failure: a report of the American College of Cardiology Foundation/American Heart Association Task Force on Practice Guidelines. J Am Coll Cardiol. 2013;62(16):e147-239. https://doi.org/10.1016/j.jacc.2013.05.019.

8. Dahl JS, Videbaek L, Poulsen MK, Pellikka PA, Veien K, Andersen LI, et al. Effect of candesartan treatment on left ventricular remodeling after aortic valve replacement for aortic stenosis. Am J Cardiol. 2010;106(5):713-9. https://doi.org/10.1016/j.amjcard.2010.04.028.

9. Inohara T, Manandhar P, Kosinski AS, Matsouaka RA, Kohsaka S, Mentz RJ, et al. Association of renin-angiotensin inhibitor treatment with mortality and heart failure readmission in patients with transcatheter aortic valve replacement. JAMA. 2018;320(21):2231-41. https://doi.org/10.1001/jama.201 8.18077.

10. Rodriguez-Gabella T, Catalá P, Muñoz-García AJ, Nombela-Franco L, Del Valle $R$, Gutiérrez $E$, et al. Renin-angiotensin system inhibition following transcatheter aortic valve replacement. J Am Coll Cardiol. 2019;74(5):631-41.

11. Goel SS, Aksoy O, Gupta S, Houghtaling PL, Tuzcu EM, Marwick T, et al. Renin-angiotensin system blockade therapy after surgical aortic valve replacement for severe aortic stenosis: a cohort study. Ann Intern Med. 2014;161(10):699-710. https://doi.org/10.7326/M13-1505.

12. Kappetein AP, Head SJ, Généreux P, Piazza N, van Mieghem NM, Blackstone $\mathrm{EH}$, et al. Updated standardized endpoint definitions for transcatheter aortic valve implantation: the Valve Academic Research Consortium-2 consensus document. Eur Heart J. 2012;33(19):2403-18. https://doi.org/10.1093/eurhea rtj/ehs 255 .

13. Ochiai T, Saito S, Yamanaka F, Shishido K, Tanaka Y, Yamabe T, et al. Reninangiotensin system blockade therapy after transcatheter aortic valve implantation. Heart. 2018;104(8):644-51. https://doi.org/10.1136/heartjnl-201 7-311738. 
14. Green CP, Porter CB, Bresnahan DR, Spertus JA. Development and evaluation of the Kansas City Cardiomyopathy Questionnaire: a new health status measure for heart failure. J Am Coll Cardiol. 2000;35(5):1245-55. https://doi.org/10.1016/S0735-1097(00)00531-3.

15. Galderisi M, Cosyns B, Edvardsen T, Cardim N, Delgado V, Di Salvo G, et al. Standardization of adult transthoracic echocardiography reporting in agreement with recent chamber quantification, diastolic function, and heart valve disease recommendations: an expert consensus document of the European Association of Cardiovascular Imaging. Eur Heart J Cardiovasc Imaging. 2017;18(12):1301-10.

16. Schulz-Menger J, Bluemke DA, Bremerich J, Flamm SD, Fogel MA, Friedrich $M G$, et al. Standardized image interpretation and post-processing in cardiovascular magnetic resonance - 2020 update: Society for Cardiovascular Magnetic Resonance (SCMR): Board of Trustees Task Force on Standardized Post-Processing. J Cardiovasc Magn Reson. 2020:22(1):19.

17. Amat-Santos IJ, Catalá P, Del Hoyo FD, Fernandez-Diaz JA, Alonso-Briales JH, Del Trigo $\mathrm{M}$, et al. Impact of renin-angiotensin system inhibitors on clinical outcomes and ventricular remodelling after transcatheter aortic valve implantation: rationale and design of the RASTAVI randomised multicentre study. BMJ Open. 2018;8(2):e020255.

18. Aboyans V, Magne J. https://clinicaltrials.gov/ct2/show/NCT03315832. Accessed 1 Jun 2021.

\section{Publisher's Note}

Springer Nature remains neutral with regard to jurisdictional claims in published maps and institutional affiliations.

Ready to submit your research? Choose BMC and benefit from:

- fast, convenient online submission

- thorough peer review by experienced researchers in your field

- rapid publication on acceptance

- support for research data, including large and complex data types

- gold Open Access which fosters wider collaboration and increased citations

- maximum visibility for your research: over $100 \mathrm{M}$ website views per year

At $\mathrm{BMC}$, research is always in progress.

Learn more biomedcentral.com/submissions 